\title{
A contribuição de Karl Mannheim para a pesquisa qualitativa: aspectos teóricos e metodológicos
}

WIVIAN WELLER

\section{Introdução}

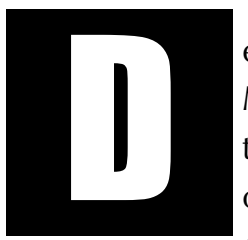

e acordo com Bohnsack (1999a), os escritos de Karl Mannheim podem ser divididos em três fases que não estão apenas relacionadas aos distintos contextos geográficos ou países em que o autor viveu, mas que apresentam produções diferentes. ${ }^{1} \mathrm{Na}$ Hungria, Mannheim dedicou-se principalmente a temas literários e filosóficos. O período em que viveu na Alemanha corresponde à fase sociológico-filosófica, abrangendo trabalhos conhecidos como "O problema das gerações" ou "Ideologia e Utopia", assim como outros trabalhos que Mannheim nunca chegou a publicar e que só chegaram ao conhecimento do público na década de 1980, com a organização do livro "Strukturen des Denkens" (Estrutura do pensamento). Já na Grã-Bretanha, onde veio a falecer em 1947, Mannheim se dedicou a análises político-pedagógicas relativas a temas emergentes naquela época, fruto de seu trabalho na área de Educação na London School of Economics and

\footnotetext{
* Doutorado em Sociologia pela Universidade Livre de Berlim. Professora do Departamento de Sociologia da UnB (Bolsa Recém Doutor/CNPq); pesquisadora do NEPEM (Núcleo de Estudos e Pesquisa sobre a Mulher) e membra do GP Violência, Cidadania e Segurança.

1 Nascido em 1893 na Hungria como filho de mãe judia-alemã e pai judeu-húngaro, Karl Mannheim iniciou seus estudos de filosofia em Budapeste, participando, na época, do grupo de estudos coordenado por Georg Lukács, que, por sua vez, integrava o gabinete de governo dirigido pelo partido comunista. Embora Mannheim não estivesse filiado ao partido, foi obrigado a deixar o país após a queda do regime, indo inicialmente para Viena e Freiburg até chegar a Heidelberg, cidade em que viveu na década de vinte do século passado. Em 1930 Mannheim assume a cadeira de Sociologia na Universidade de Frankfurt, tendo Norbert Elias como seu assistente. Com a ascensão do regime nacional socialista e a introdução de leis que proibiam o exercício de cargos
} 
Political Science. ${ }^{2}$ Segundo Bohnsack (op. cit.), existem pelo menos três razões que justificam a retomada ou releitura do pensamento de Mannheim neste início de século:

- a associação do conhecimento e do pensamento ao contexto local (Standortgebundenheit oder Verbundenheit des Wissens und Denkens), que Mannheim denomina de "conhecimento conjuntivo" (cf. Kettler et al., 1982);

- as reflexões metodológicas e o desenvolvimento de um método de análise da ação e/ou das práticas cotidianas que vão além da teoria do indivíduo, sobre a sua ação e suas intenções. Nesses escritos, o autor aponta os tipos de interpretação sociológica e apresenta o método documentário de interpretação como essencial para a transcendência da postura imanente para a postura sociogenética (cf. Mannheim, 1952 e 1982);

- sua contribuição na definição de conceitos como geração, ${ }^{3}$ meio social (milieu), estilo e habitus (ib.). ${ }^{4}$

Na seqüência, focaremos alguns escritos sociológico-filosóficos, destacando o método de análise das visões de mundo ou representações coletivas e a adaptação da proposta metodológica de Mannheim para a pesquisa social empírica.

\section{Karl Mannheim e o método documentário de interpretação}

Em seu artigo Contribuições para a teoria da interpretação das visões de mundo (Beiträge zur Theorie der Weltanschauungsinterpretation), publicado originalmente em 1921/22, Mannheim apresenta um método ou um

\footnotetext{
públicos por judeus, Mannheim é demitido da Universidade de Frankfurt e vê-se novamente obrigado a emigrar. 2 Uma compilação dos principais escritos de Mannheim foi organizada por Yncera, 1993, p. 245-253.

3 Sobre a relevância do ensaio “O problema das gerações” publicado por Mannheim em 1928 cf. Yncera, 1993b, p. 147-192. 4 Para Espinosa a retomada do pensamento de Mannheim se justifica "sobre todo porque el problema esencial de nuestra época (y de nuestro pensamiento) deriva de una gigantesca globalización mundial del mismo problema que atenazaba a Mannheim: el choque de concepciones del mundo, el pluralismo cultural, el etnocentrismo (o eurocentrismo) y su contraste, el relativismo, la deconstrucción de la razón en "discursos" y "narrativas", la pérdida de referencia en la objetividad" (1993, p. 10s).
} 
caminho para a indicialidade ${ }^{5}$ dos espaços sociais e compreensão das visões de mundo de um determinado grupo. Weltanschauung (visão de mundo) segundo Mannheim - é o resultado de "uma série de vivências ou de experiências ligadas a uma mesma estrutura, que por sua vez constitui-se como base comum das experiências que perpassam a vida de múltiplos indivíduos" (1980, p. 101). No entanto, não podemos confundir visões de mundo com imagens de mundo ou com algo que tenha sido pensado ou produzido teoricamente: as visões de mundo são construídas a partir das ações práticas e pertencem ao campo que Mannheim definiu como sendo o do conhecimento ateórico (id. 1964, p. 97ss). Nesse sentido, a compreensão das visões de mundo e das orientações coletivas de um grupo só é possível através da explicação e da conceituação teórica desse conhecimento ateórico. O grupo envolvido geralmente não está em condições de realizar essa tarefa, ou seja; a explicação teórica do conhecimento ateórico é praticamente impossível para o indivíduo ou grupo vinculado ao contexto em que se construiu esse saber. O papel do(a) pesquisador(a) passa a ser, então, encontrar uma forma de acesso ao conhecimento implícito do grupo pesquisado, explicitá-lo e defini-lo teoricamente.

Do ponto de vista metodológico, a diferenciação tecida por Mannheim entre interpretação imanente e interpretação genética e sua reivindicação por uma mudança radical na forma de análise foram fundamentais (id. 1980, p. 85-88). Em outras palavras, pode-se dizer que, nessa diferenciação, ao invés da pergunta o que (was) é uma realidade social, deveremos perguntar como ou de que forma (wie) essa realidade social está constituída (cf. Bohnsack, 2001, p. 326; Mannheim, 1964, p. 134). Mannheim define a transcendência da pergunta o quê para a pergunta como ou de que forma, como postura sociogenética ou funcional (id. 1980, p. 71-79). A compreensão funcional ou interpretação genética é distinta da interpretação imanente da realidade social, ou seja, da compreensão intuitiva que desenvolvemos

5 Termo adaptado da lingüística pela Etnometodologia cf. Coulon, 1995. 
no cotidiano. Segundo Mannheim, no processo de interpretação existem ainda três "níveis de sentido" (Sinnschichten) a serem diferenciados:

- um nível objetivo ou imanente, dado naturalmente (por exemplo, num gesto, num símbolo ou ainda na forma de uma obra de arte);

- um nível expressivo, que é transmitido através das palavras ou das ações (por exemplo, como expressão de ou como reação a algo);

- e um nível documentário, ou seja, como documento de uma ação prática (id. 1964, p. 103-129).

Buscando esclarecer as diferenças entre os três níveis de sentido de um produto cultural, Mannheim comenta que: ${ }^{6}$

Inicialmente é necessário apontar as diferenças e o lugar em que se encontram. Se olharmos para um "objeto natural", veremos à primeira vista, aquilo que o caracteriza (...) Um produto cultural, por outro lado, não pode ser compreendido em seu próprio e verdadeiro sentido se nos atemos simplesmente sobre aquele "nível de sentido" que ele transmite quando o olhamos inteiramente em seu sentido objetivo. É necessário considerar seu sentido expressivo e documentário, se quisermos esgotar inteiramente seu significado (p. 44/104).

Desta forma, todo produto cultural apresenta em sua totalidade os três níveis ou estratos distintos de significação, passíveis de serem revelados pelas análises científicas. Diferentemente do objeto natural, no qual é possível perceber ou intuir uma caracterização bastante próxima de sua constituição real num primeiro olhar, o produto cultural necessita de uma análise que considere os três níveis de interpretação. Não é possível compreender uma obra de arte se percebermos apenas o nível objetivo ou imanente; temos que compreender também os sentidos expressivo e

6 A tradução das citações para o português foi realizada com base no texto original e sua tradução para o inglês, tratando-se de uma livre tradução na qual adotamos o seguinte critério: o número da pág. da tradução para o inglês, seguido do número da pág. da versão alemã cf. Weller et al., 2002. 
documentário, se quisermos esgotar as possibilidades de análise e transcender sua significação imediata. Alcançar os outros níveis de sentido é tarefa fundamental para compreender as manifestações de qualquer produto cultural em sua totalidade (p. 44/105).

Os diferentes níveis de sentido estão presentes não somente nos produtos culturais tradicionalmente prestigiados como a arte ou a religião, mas também nas ações cotidianas comumente despercebidas. Mannheim apresenta-nos um exemplo trivial, tomado do cotidiano:

Estou caminhando com um amigo por uma rua em cuja esquina se encontra um mendigo. Meu amigo dá uma esmola. Não interpreto seu ato, de forma alguma, como um fenômeno físico ou fisiológico, mas como portador de um sentido, que, nesse caso, significa "ajuda". Neste processo de compreensão é atribuído ao ato um sentido que, na esfera sociológica, é fixado ou definido teoricamente como "ajuda social". Se analisado no contexto social, o senhor que estava à nossa frente passa a ser um "mendigo", meu amigo um "ajudante", e o objeto de metal em suas mãos vira uma "esmola". O objeto cultural, nesse caso, é o sentido identificado ou definido sociologicamente como "ajuda"; meu amigo não é visto como um indivíduo fisiológico com características próprias, mas apenas como um "ajudante", como parte de uma situação apreendida, que, em si só, seria a mesma se no seu lugar estivesse uma outra pessoa (p. 45/105s).

Segundo o autor, a compreensão do sentido "ajuda" - que, no caso, seria o sentido objetivo - não pressupõe o conhecimento do mundo interior (Innenwelt) do amigo nem da vida do mendigo, mas apenas o conhecimento do contexto social objetivo através do qual e no qual existem "mendigos" e "senhores de bem". Um sentido objetivo dessa natureza existe em qualquer produto cultural, e a sua compreensão não exige o conhecimento 
dos atos intencionais do ator individual e do produto da manifestação (p. 45s/106).

Outrossim é possível e provável que o amigo não tenha sido movido apenas pela intenção de ajudar, mas também de demonstrar ao observador ou ao mendigo um gesto de "compaixão". Neste caso, o portador do sentido objetivo também passa a ser portador de um sentido totalmente novo, que nem sempre pode receber um nome fixo, mas que poderia ser definido como "misericórdia", "bondade" ou "pena". O gesto de "dar uma esmola" recebe aqui um outro sentido além do sentido objetivo denominado como "ajuda". Essa segunda motivação - sentido expressivo - diferencia-se do primeiro, por não poder ser interpretado independentemente do sujeito e de seu contexto, ou seja, a verdadeira razão do ato de "dar esmola" só será compreendida se tivermos acesso ao mundo interior do sujeito que a ofereceu e ao meio social ao qual pertence (p. 46/107s).

Poderíamos pensar que as possibilidades de interpretação se tenham esgotado, mas o exemplo acima revela ainda uma outra dimensão: é possível que a análise da situação observada tome uma direção totalmente diferente, levando, por exemplo, à conclusão de que a esmola oferecida tenha sido um ato de "hipocrisia". Neste nível de interpretação, o sentido objetivo, assim como as intenções imbuídas na ação não são relevantes para a análise: o que interessa nesse terceiro nível de interpretação é a descoberta do sentido documentário da ação, ou seja, a análise do que esse ato, mesmo sem querer, documenta ou revela sobre a pessoa que ofereceu a esmola. A partir do momento em que a ação passa a ser um documento para a interpretação teórica, ou seja, a partir do momento em que o ato de dar esmolas foi interpretado teoricamente como "hipocrisia", o sentido da ação continua sendo objeto de interpretação, mas de forma distinta daquelas realizadas até o momento. A mesma técnica de interpretação pode ser aplicada na análise de outras manifestações de sua personalidade, tais como: suas expressões faciais, seus gestos, seu modo de andar, seu ritmo de discur- 
so. Assim sendo, a interpretação não deve permanecer no nível da análise das intenções de quem ofereceu a esmola (sentido expressivo) ou ainda no nível da análise do caráter proposital da esmola (sentido objetivo). É preciso salientar que este método de análise dos produtos culturais ou de situações da vida e ações cotidianas é constantemente utilizado, lembrando que o último nível de interpretação (o documentário) oferece uma forma de compreensão imprescindível e que não pode ser confundido com os dois primeiros níveis. No entanto, o sentido expressivo e o sentido objetivo não são excludentes, mas, metodologicamente, são etapas necessárias para a reconstrução do sentido documentário, sendo que esse último nível de interpretação só poderá ser apreendido a partir da Jetzt-Perspektive, ou seja, do contexto histórico e social atual no qual o pesquisador está inserido (p. 61/126).

De acordo com Mannheim, a postura genética é fundamental para a compreensão e explicação do sentido documentário das visões de mundo ou das orientações coletivas dos membros, um grupo, bem como do modus operandi de suas ações. $\mathrm{O}$ acesso ao sentido documentário de uma frase ou de uma expressão cultural só é possível a partir do processo de interpretação e, por isso, podemos afirmar que ele só acontece de forma receptiva (id. 1964, p. 118). Este caminho implica tanto a exploração de uma via de acesso ao "psíquico do outro" (Fremdpsyche) como a inserção no contexto social que, por sua vez, possibilitará a compreensão desse espaço social de experiências conjuntivas (konjunktiver Erfahrungsraum) e de suas respectivas representações coletivas (id. 1980, p. 271). Em outras palavras, o autor afirma que o sentido documentário de uma frase ou de uma expressão cultural está inserida num contexto específico e que, para entendermos o seu significado, é preciso encontrar uma forma de inserção nesse contexto específico (por exemplo, através do trabalho de interpretação), não apenas para conhecê-lo, mas para compreender o significado de determinadas expressões e representações sociais. Neste processo, Mannheim destaca ain- 
da a análise da linguagem e da mudança dos significados das palavras como aspectos fundamentais para a compreensão das mudanças estruturais e transformações do meio social (cf. García, 1993, p. 66). Ao trazer como proposta metodológica a interpretação documentária da linguagem e do sentido das ações e/ou das práticas cotidianas, Mannheim propõe uma abordagem que vai além da teoria do indivíduo sobre a sua ação e suas intenções, afirmando que é preciso transcender o nível de análise intuitiva ou dedutiva do objeto em questão.

\section{A adaptação do método documentário de interpretação para a pesquisa qualitativa}

Conhecido como autor que cunhou o termo Etnometodologia, Garfinkel (1967) também foi o primeiro a reconhecer a importância do método documentário de interpretação de Karl Mannheim, como uma forma de análise das visões de mundo e como elemento chave para a compreensão das ações e da organização social (cf. Coulon, 1995; Heritage, 1999). O movimento etnometodológico resgatou um autor que, de certa forma havia caído no esquecimento, e instigou um novo olhar sobre os escritos de Mannheim da década de 1920. Contudo a Etnometodologia fez um uso restrito do método documentário de interpretação, utilizando-o como forma de decodificar os "métodos" ou regras que estruturam a vida numa determinada localidade (cf. Meuser, 2001). Tal procedimento, restrito à análise das normas sociais que orientam as ações dos atores, dificulta uma ampla apreensão do sentido documentário de uma determinada ação ou comportamento. Segundo Meuser, a Etnometodologia não chegou a desenvolver instrumentos ou métodos de análise específicos. Ao mesmo tempo suas análises carecem de abordagens multidimensionais que avaliem a influência de outros aspectos na construção de determinadas normas sociais, tais como as relações geracionais, étnicas e de gênero, o meio social, a formação escolar e profissional (id. p. 214ss). 
Uma outra leitura e aplicação do método documentário de interpretação foi desenvolvida pelo sociólogo Ralf Bohnsack (entre outros: 1999 e 2001a). Com base na diferenciação dos três "níveis de sentido" apresentados por Mannheim, Bohnsack atualizou a interpretação documentária, tanto do ponto de vista do método como da metodologia, e a transformou em um instrumento de análise para a pesquisa social empírica de caráter reconstrutivo. Bohnsack coloca a reconstrução do terceiro nível de sentido no centro da análise empírica, o que significa que, ao invés da reconstrução do decurso de uma ação (nível objetivo ou imanente), passaremos a analisar e reconstruir o sentido dessa ação no contexto social em que está inserida (nível documentário). A busca pelo sentido documentário implica uma "observação de segunda ordem" (cf. Luhmann, 1990, p. 68-121) que possibilita o acesso ao conhecimento pré-reflexivo ou ao "conhecimento tácito" dos atores (cf. Polanyi, 1985; Bohnsack, 2001). O nível documentário pressupõe uma mudança na postura do observador que, ao invés de lançar a pergunta o quê, irá perguntar pelo como, ou seja: como a prática que está sendo observada é produzida ou realizada? Nessa transcendência da pergunta o quê para a pergunta como - denominada por Mannheim como postura sociogenética ou funcional (op. cit. ) - o modus operandi da ação prática passa a ser um dos principais elementos da análise.

Por exemplo, na interpretação documentária da prática musical e artística de jovens pertencentes ao movimento hip hop - cujos passos serão apresentados na seqüência - não é a interpretação da música e de seu sentido expressivo que está em primeiro lugar, mas sobretudo a análise das orientações coletivas em um determinado contexto social ou milieu, que se constituíram a partir da articulação desses jovens neste movimento cultural. O método documentário como teoria e prática da interpretação sociológi$\mathrm{Ca}^{7}$ pode ser visto como um instrumento que auxilia na inserção do(a)

\footnotetext{
7 Embora fortemente influenciado pela Sociologia do Conhecimento, outros aportes teórico-metodológicos foram fundamentais para o desenvolvimento e adaptação do método documentário para a análise de dados qualitativos, sendo eles a Fenomenologia Social, o Interacionismo Simbólico, a Escola de Chicago e a Etnometodologia.
} 
pesquisador(a) em contextos sociais que Ihe são alheios, assim como na compreensão e conceituação de suas visões de mundo, suas ações e formas de representação.

A interpretação documentária não parte de teorias ou metodologias elaboradas previamente: essas são desenvolvidas ou incorporadas de forma reflexiva durante o processo da pesquisa. A reconstrução constitui uma das principais ferramentas do método documentário de interpretação desenvolvido por Ralf Bohnsack, diferenciando-se, desta forma, de outras abordagens qualitativas e/ou métodos "estandardizados", que se caracterizam pela elaboração prévia de hipóteses e pela verificação ou comprovação destas no processo de interpretação. ${ }^{8} \mathrm{~A}$ análise documentária tem como objetivo a descoberta ou indicialidade dos espaços sociais de experiências conjuntivas do grupo pesquisado, ${ }^{9}$ a reconstrução de suas visões de mundo e do modus operandi de suas ações práticas. Para tanto, a diferenciação entre compreensão (Verstehen) e interpretação (Interpretieren) é fundamental:

La interpretación se ocupa de la más profunda comprensión del sentido. La explicación genético-causal proporciona la historia de las condiciones de la actualización y la realización del sentido. Sin embargo, el sentido mismo no puede ser, en última instancia, explicado causalmente. El sentido en su contenido más auténtico sólo puede ser comprendido o interpretado (Mannheim, 1964, p. 151; cit.em: Muñoz, 1993, p. 53).

\footnotetext{
8 Na Alemanha, este enfoque metodológico surgiu na década de 1980 juntamente com outras abordagens qualitativas de caráter reconstrutivo como a "Objektive Hermeneutik" (hermenêutica objetiva) de Ulrich Oevermann e a "Erzählanalytische Verfahrensweise" (método de interpretação analítica) de Fritz Schütze. Estes enfoques se foram consolidando a partir de diversas premissas, tais como: o princípio da abertura, da comunicação, da processualidade, da reflexividade, da explicação e da flexibilidade (cf. Neves, 1998, p. 7ss).

9 Para Mannheim, as experiências conjuntivas ou o conhecimento conjuntivo constituem uma característica "de la vida de una comunidad cohesionada en torno a una visión del mundo, que sería fruto, a su vez, de la experiencia vital compartida" (Yncera, 1993, p. 29). Esse conhecimento se opõe ao saber comunicativo ou às experiências comunicativas, que seriam "ese modo abstracto de intercambio de experiencias entre esferas culturales heterogéneas y disgregadas entre sí, propio de una sociedad desarollada y carente de unidad cultural" (id.).
} 
A explicação teórica do conhecimento ateórico - como já dizia Mannheim - pressupõe um trabalho de interpretação e passa a ser tarefa do(a) pesquisador(a). No entanto, esse conhecimento também pode ser compreendido sem uma explicação, ou seja, sem uma interpretação entre aqueles que compartilham do mesmo espaço social de experiências conjuntivas. Os jovens pertencentes ao movimento hip hop de um mesmo bairro por exemplo, compreendem-se uns aos outros pela referência sucessiva ao conhecimento tácito, sem necessidade alguma de interpretarem uns aos outros. Isso é o que Mannheim (1980) definiu como compreensão (Verstehen).

Diferente da compreensão, a interpretação, ou seja, a explicação teórica do modus operandi que orienta a ação prática, e através do qual o padrão de orientação é constituído e reproduzido, requer uma linha ou instância específica de análise - uma postura sociogenética - que pergunta pelo como. ${ }^{10}$ Essa instância analítica está associada também a um "colocar entre parênteses o caráter de validade" dos fatos sociais ("Einklammerung des Geltungscharakters" - Mannheim, 1980, p. 88). Colocar entre parênteses significa suspender a reivindicação pela verdade ou autenticidade normativa das histórias narradas. Nesse sentido, a veracidade dos fatos narrados ou mesmo a índole do informante não constituem objeto de preocupação da análise documentária: a tarefa do pesquisador consiste no questionamento daquilo que está documentado nas descrições dos entrevistados sobre suas atitudes, seus habitus e padrões de orientação (cf. Bohnsack, 2002).

\footnotetext{
10 Não estamos afirmando que apenas o pesquisador está em condições de realizar o trabalho de interpretação, ou seja, de explicação teórica do conhecimento ateórico. Os jovens pertencentes ao movimento hip hop compreendem-se uns aos outros e também realizam interpretações sobre suas práticas (cf. Weller, 2003 e 2003a). No entanto, por mais familiarizado que se esteja com o ambiente e atores da pesquisa, a reconstrução da realidade observada sempre implicará um processo de interpretação. A ausência desse processo e o controle do próprio processo de interpretação poderão implicar a elaboração de explicações causais sobre os fatos observados.
} 


\section{Etapas da análise empírica segundo o método documentário de interpretação}

Antes de apresentarmos os procedimentos da análise de entrevistas, faremos uma breve contextualização da pesquisa em que esse método foi aplicado. Trata-se de um estudo realizado com jovens pertencentes ao movimento hip hop nas cidades de São Paulo e Berlim, cujos resultados foram apresentados como tese de doutorado junto ao Departamento de Sociologia da Universidade Livre de Berlim (cf. Weller, 2003). Desde os primeiros contatos com jovens negros em São Paulo e com jovens de origem turca em Berlim, ou seja, durante a fase de construção do projeto, ${ }^{11}$ foi possível verificar que o hip hop se havia constituído num espaço de partilha de experiências e de elaboração de estratégias de enfrentamento do racismo e do preconceito. Durante a pesquisa, buscou-se compreender as visões de mundo desses jovens e a forma como estilos culturais globalizados são apropriados e ressignificados. Ao mesmo tempo, esse estudo sobre a gênese, estrutura e função dos grupos juvenis analisou a importância destas práticas culturais na construção de identidades, no enfrentamento da segregação social e da discriminação étnica e/ou religiosa. Nesse sentido, foi elaborado um conjunto de questões que orientaram a escolha das técnicas e os procedimentos de coleta e análise dos dados:

1. Qual a importância da práxis musical e artística do hip hop nesses meios sociais? Que tipo de orientações coletivas ou visões de mundo emergem dessas práticas?

2. Qual a função do grupo juvenil (peergroup) nos distintos contextos?

3. Apesar das diferenças históricas, políticas e sociais entre ambos países e das diferenças culturais entre jovens paulistanos e berlinenses, é possível encontrar semelhanças com relação aos modelos de orientação ou visões de mundo dos mesmos?

11 A escolha do objeto de pesquisa resultou de estágios, pesquisas e trabalhos realizados anteriormente nas cidades de São Paulo e Berlim. Minha experiência como auxiliar de pesquisa e docência no Instituto de Educação Intercultural da Universidade Livre de Berlim (1993 a 1996) teve forte influência na construção do projeto de pesquisa. 
4. Como se posicionam em relação ao grupo étnico? Como discutem imagens e definições relativas ao pertencimento étnico (tanto aquelas atribuídas externamente como as que são construídas pelo grupo)?

5. Como estão constituídas as relações interétnicas no cotidiano, e que leitura fazem das relações étnico-raciais em ambos países?

6. De que forma são vividas as práticas de discriminação e denegrição? Quais são as conseqüências destas experiências? É possível identificar estratégias de enfrentamento dessas situações?

Para tanto, foram realizadas, no período de 1998 a 2000, um total de quinze entrevistas de grupo e quinze entrevistas biográfico-narrativas (história de vida) com grupos de rap de ambas as cidades. Como procedimento de coleta de dados, fizemos uso ainda da observação participante e da coleta de material audiovisual e impresso sobre os grupos, tais como CDs, vídeos de apresentações realizadas, artigos de jornais e fanzines. Essa triangulação de métodos ou de técnicas de coleta de dados foi fundamental para a análise em profundidade das entrevistas de grupo que constituíram a principal fonte na fase de reconstrução das visões de mundo dos jovens pertencentes ao movimento hip hop e das práticas de enfrentamento das discriminações e desigualdades. As entrevistas biográfico-narrativas (cf. Jovchelovitch \& Bauer, 2002) foram realizadas, por um lado, com o objetivo de conhecer o meio social e o contexto familiar dos jovens entrevistados, e, por outro, de compreender a importância do grupo na trajetória de vida do entrevistado (cf. Weller, 2003). Tanto as entrevistas de grupo como as entrevistas individuais foram analisadas segundo o método documentário de interpretação, cujas etapas estaremos apresentando a seguir.

A análise de entrevistas segundo o método documentário de interpretação

Como vimos anteriormente, Mannheim afirma que a transição do sentido imanente para o documentário implica uma mudança da pergunta 
o quê para a pergunta como. Tal procedimento não exclui a pergunta pelo o quê durante o processo de análise de entrevistas, mas exige um tratamento distinto da pergunta pelo como. Esta diferença metodológica entre o sentido imanente e o sentido documentário corresponde à diferença entre as observações de primeira e segunda ordem, que em termos práticos, é realizada em duas etapas, denominadas por Bohnsack (op. cit.) como interpretação formulada e interpretação refletida. ${ }^{12}$

A interpretação formulada compreende diferentes estágios, dos quais destacamos: a) a organização dos tópicos discutidos na entrevista (cf. anexo I); b) a seleção e transcrição dos temas (ou passagens) que serão analisadas; c) a análise detalhada do sentido imanente. Além da organização temática, a interpretação formulada busca decodificar a linguagem coloquial utilizada na entrevista. Em outras palavras, o(a) pesquisador(a) reescreve o que foi dito pelo(a)s informantes, trazendo o conteúdo de suas falas para uma linguagem que também poderá ser compreendida por aquele(a)s que não pertencem ao meio pesquisado. Nesta etapa de análise o(a) pesquisador(a) não faz comentários e tampouco remete ao conhecimento que possui sobre o grupo ou meio pesquisado, como podemos verificar no quadro abaixo: ${ }^{13}$

\footnotetext{
12 Embora Mannheim tenha chamado a atenção para a existência de três níveis de sentido, que se fazem presentes num objeto cultural ou numa ação cotidiana como, por exemplo, no ato de oferecer uma esmola, o segundo nível de interpretação, ou seja, o sentido expressivo, não é objeto de interpretação do método documentário adaptado para a pesquisa qualitativa, uma vez que empiricamente não nos é possível reconstruir o sentido expressivo. Mesmo em situações nas quais os informantes descrevem as intenções que motivaram suas ações, estas não podem ser observadas pelo pesquisador. Toda e qualquer análise do sentido expressivo seria de caráter indutivo ou dedutivo. O método documentário orienta-se, no entanto, pelo princípio da abdução (no sentido dado por Charles S. Peirce), que é um processo "utilizado para gerar relatos [accounts] científico-sociais a partir dos relatos dos atores sociais; para originar conceitos técnicos e teóricos com base em conceitos leigos e na interpretação da vida social" (Blaskie, 1993, p. 114). Sobre a utilização do método abdutivo na pesquisa qualitativa cf. Reichertz, 2003.

13 A transcrição completa do segmento selecionado para a análise, bem como os códigos utilizados na transcrição da entrevista de grupo encontram-se nos anexos II e III.
} 
Entrevista com o grupo paulistanos Skateboard (nome fictício)

\section{Divisão temática da passagem hip hop}

Linhas: Temas principais (TP)

1-67 Diferenças entre a banda Skateboard e outras bandas

69-133 Motivação e interesse pelo hip hop

134-151 Significado do hip hop: "O rap fala a vida de cada um"

\section{Interpretação formulada}

Obs.: devido ao limite de pág. do artigo, restringimos-nos à análise das linhas 69 a 151.

\section{Segmento 69 - 133: Motivação e interesse pelo hip hop}

69 - 81 Subtema (ST): Preferência pelo estilo e pela cultura hip hop

$\mathrm{Y}$ introduz uma pergunta relacionada ao interesse pelo hip hop. Para $B m$ foi principalmente o estilo que o levou a se interessar pelo hip hop. Também a convivência no grupo foi um fator importante: Escutar música com seus amigos na escola proporcionava descontração e despertou o interesse pela "cultura".

82 - 93 Identificação com a variedade de estilos e com as letras

$\mathrm{Cm}$ destaca a variedade de estilos e os temas discutidos nas letras como motivo gerador de sua identificação com o hip hop. Cada integrante aprendeu um pouco com cada estilo, o que possibilitou a formação da banda Skateboard.

94 - 108 Distintas formas de ingresso no movimento "hip hop"

O gosto e o prazer proporcionado pela música foi o que motivou alguns integrantes. Outros haviam participado anteriormente do movimento break na estação São Bento e freqüentado atividades desenvolvidas pela Posse Sindicato Negro na praça Roosewelt.

108 - 122 Surgimento de um movimento juvenil na periferia e fundação da Posse Estilo Negro

O contato com a Posse Sindicato Negro no centro da cidade impulsionou a criação de um movimento semelhante na Cohab Fernandes. Am 
planejou, juntamente com Carlos, a criação da Posse Estilo Negro. Tinham nesse momento a pretensão de serem os pioneiros na divulgação do hip hop na periferia. O nome da posse surge posteriormente, como forma de identificação. Como a maioria de seus integrantes eram/são negros optou-se pelo nome Estilo Negro.

122 - 133 Ingresso no movimento através da dança, do grafite, da música e do trabalho comunitário

Conhecendo os diferentes elementos do movimento, os jovens passaram a ver que o hip hop não era apenas um estilo musical, mas muito mais do que isso. A banda Skateboard surgiu deste processo de conhecimento dos diferentes aspectos que fazem parte do hip hop e da identificação com as letras cantadas ao ritmo do rap.

\section{Segmento 134 a 151 - Significado do hip hop: “O rap fala a vida de cada um"}

134 - 140 Rap como estilo musical próximo da realidade e como forma de expressão

Por ser um estilo que retrata as situações vividas no contexto social, existe uma forte identificação com o rap, principalmente entre jovens que possuem uma "mente revolucionária". Ao contrário da MPB, o rap traduz a realidade de forma direta, ou seja, sem escamotear ou encobrir os fatos.

141 - 151 Rap como uma forma de desabafo

O rap é também uma forma de desabafo para os jovens. As letras falam de experiências pessoais, por exemplo, da morte da avó, ou de problemas vividos na relação entre pais e filhos.

A escolha deste segmento como ilustração das etapas da interpretação formulada corresponde, por um lado, ao tema central de minha pesquisa (importância da práxis musical e artística do hip hop), e, por outro, por se 
tratar do primeiro tema discutido na entrevista. A transcrição e análise da passagem inicial revela aspectos importantes sobre a interação entre entrevistador(a)/entrevistados e auxilia na identificação do "quadro de referência" do grupo (vide abaixo). A entrevista deve ser iniciada com uma questão que instigue a discussão entre os integrantes do grupo, estimule a narração de experiências vividas e não a mera descrição de fatos, procedimento este que deve ser mantido ao longo de toda a entrevista. Durante a discussão de um determinado tema o(a) pesquisador(a) deve manter-se na posição de ouvinte, interferindo somente quando solicitado (por ex.: no momento em que o grupo sinaliza que determinado assunto já foi discutido exaustivamente e sugere a formulação de uma nova pergunta), ou em situações que exigem a retomada da condução da entrevista (cf. anexo III). As possibilidades de análise, tanto no nível da interpretação formulada como no da interpretação refletida, dependem da qualidade do material empírico. Neste sentido, o conhecimento sobre o meio pesquisado, assim como o cuidado metodológico na condução da entrevista, são fundamentais.

Já a interpretação refletida implica uma observação de segunda ordem, na qual o(a) pesquisador(a) realiza suas interpretações, podendo recorrer ao conhecimento adquirido sobre o meio pesquisado (cf. anexo IV). Enquanto a interpretação formulada analisa a estrutura básica de um texto (organização temática), a interpretação refletida busca analisar tanto o conteúdo de uma entrevista como o "quadro de referência" (frame), que orienta a fala, as ações do indivíduo ou grupo pesquisado e as motivações que estão por detrás dessas ações. Goffman (1996) se refere ao termo "quadro" (frame) como um

dispositivo cognitivo e prático de organização da experiência social que nos permite compreender e participar daquilo que nos acontece. Um quadro estrutura não só a maneira pela qual definimos e interpretamos uma situação, mas também o modo como nos engajamos

14 Sobre a análise dos quadros de Goffman vide Fabiani, 2002, p. 51-54. 


$$
\text { numa ação (Joseph, 2000, p. 94). }{ }^{14}
$$

A interpretação refletida tem por objetivo a reconstrução deste "quadro de orientação", ou seja, do habitus. ${ }^{15} \mathrm{Na}$ análise de uma entrevista de grupo, o primeiro momento da interpretação refletida é dedicado à reconstrução da organização do discurso, à análise da interação entre os(as) participantes, por exemplo, a forma como se referem uns aos outros ou uma às outras, a dramaturgia e a densidade do discurso. Durante a interpretação refletida, quer dizer, no processo de explicação de uma norma, de um modelo ou quadro de orientação o(a) pesquisador(a) busca analisar não somente questões temáticas que possam parecer interessantes, mas também padrões homólogos ou aspectos típicos do meio social. No entanto a reconstrução de um modelo de orientação comum só poderá ser realizada através da comparação com outros grupos. Neste sentido, a análise comparativa constitui um dos princípios básicos do método documentário de interpretação. Toda interpretação somente passará a ganhar forma e conteúdo quando realizada e fundamentada na comparação com outros casos empíricos. Somente através desse procedimento o(a) pesquisador(a) poderá caracterizar uma fala, comportamento ou ação como algo típico para determinado grupo ou meio social.

Análise comparativa e construção de tipos

A comparação constante, como método de investigação empírica (constant comparative method) foi introduzida na década de 1960 por Glaser \& Strauss (1967) que lançaram as bases do que ficou sendo conhecido como "teoria fundamentada" ou Grounded Theorie (cf. Glaser \& Strauss, 1967; Mella, 1998). De acordo com Glaser \& Strauss este método possibilita, por um lado, a generalização dos resultados obtidos através da pesquisa, e, por outro, a elaboração de teorias fundamentadas em dados empíricos.

15 Sobre o conceito de habitus vide entre outros: Ortiz, 1983. 
Segundo Mella, a teoria fundamentada procura

eliminar la distancia entre las grandes tradiciones teoréticas en ciencias sociales y la investigación empírica. Se trata por tanto de enfatizar la calidad de generación de teoría más que la verificación de teoría, puesto que se plantea que los esfuerzos han sido puestos en demasía en lo primero en vez de lo segundo. La fuente para la generación de teoría es el dato empírico y el método es el análisis comparativo (1998, p. 69).

Para o método documentário de interpretação, a análise comparativa tem como objetivo a reconstrução dos aspectos homólogos entre diferentes casos estudados (por exemplo, entre diferentes entrevistas). Quanto mais precisa for a análise, mais exatas serão as afirmações realizadas com base nos dados empíricos que, por sua vez possibilitarão a construção de tipos, por exemplo, dos tipos de estratégias desenvolvidas por jovens negros em São Paulo e jovens de origem turca em Berlim para enfrentar problemas como o racismo e o preconceito (cf. Weller, 2002 e 2004). O processo de tipificação está diretamente associado ao universo de comparação do(a) pesquisador(a) e a forma como este(a) constrói o 'tertius comparativo':

Um elemento central da metodologia comparativa no sentido dado pelo método documentário de interpretação diz respeito ao modo como o tertius comparativo é constituído. Mesmo sendo um método que se define explicitamente como comparativo, nós nos deparamos com o problema da 'mancha cega' ['blinder Fleck' - o autor utiliza um conceito de Luhmann], principalmente quando se trata de definir o tertius comparativo (Bohnsack, 1999, p. 210).

A fim de evitar o problema da 'mancha cega' ou de uma seleção inadequada da amostra, a escolha dos casos que serão comparados é realizada, num primeiro momento, através de critérios objetivos que, de certa 
forma, estruturam o processo de coleta e constituição do corpus da pesquisa, entre outros: a faixa etária, o sexo, a profissão, as práticas político-culturais (grupos musicais, ambientalistas, movimentos anti-globalização). Essa estruturação da amostra facilita a procura por aspectos homólogos entre os diferentes casos estudados. Entretanto, o tertius comparativo não resulta da análise de critérios objetivos, mas dos dados obtidos no processo de interpretação, o que constitui um segundo momento da comparação (cf. Nohl, 2001). Através do tertius comparativo, por exemplo, dos resultados obtidos na análise de duas ou mais entrevistas, os contrastes entre os casos aparentemente homogêneos tornam-se evidentes. Neste sentido, a análise comparativa é um procedimento que se orienta pelo princípio da busca por contrastes em casos homólogos. Na pesquisa realizada com grupos pertencentes ao movimento hip hop em São Paulo e Berlim, os contrastes tornaramse evidentes durante a comparação e análise dos temas discutidos pelos grupos. Foi possível verificar, por exemplo, que as visões de mundo e ações coletivas dos jovens não estão propriamente vinculadas ao contexto local ou cultural, mas que transcendem este tipo de fronteira. Em ambas as cidades, dois tipos de grupos foram encontrados: por um lado, grupos que se caracterizam por sua orientação geracional - que associam suas práticas e discursos à geração a qual pertencem - e, por outro, grupos de orientação social-combativa - que vêem no hip hop uma forma de articulação/ conscientização dos jovens e de concretização de suas aspirações sociopolíticas (cf. Weller, 2003 e 2004). Análises e interpretações com base na comparação de casos e não em teorias previamente elaboradas ou em informações divulgadas na mídia fazem-se necessárias principalmente nos estudos das práticas cotidianas. ${ }^{16}$

As perspectivas do pesquisador sobre o como, sobre o modus operandi das práticas cotidianas que constitu- 
em a realidade social, dependem de suas possibilidades e de seus universos de comparação. O modus operandi a ser analisado ... ganhará contornos, ou seja, sua seletividade específica somente se tornará visivel, se nós, enquanto intérpretes, dispusermos de universos de comparação alternativos (Bohnsack \& Nohl, 2001b, p. 31).

De acordo com Mannheim (1952), a interpretação não é neutra e estará sempre associada à formação teórica, assim como ao pertencimento geográfico e social daquele que interpreta (Standortgebundenheit oder Seinsverbundenheit des Denkens). Não é possível excluir o conhecimento e as experiências adquiridas ao longo da vida do processo de análise. Neste sentido, Bohnsack \& Nohl (op. cit. p. 31) afirmam que a interpretação estará sempre vinculada às experiências cotidianas do(a) pesquisador(a), que, por sua vez, estão relacionadas aos seus vínculos sociais, geracionais e de gênero, à sua formação intelectual, entre outros. No entanto o método comparativo exerce uma forma de controle sobre o conhecimento teórico e a posição que o(a) pesquisador(a) ocupa na esfera social, na medida em que o meio social e o conhecimento implícito do grupo estudado é analisado através da comparação com outro caso. Desta forma, o conhecimento ateórico que orienta as ações de um grupo é reconstruído com base nos dados obtidos através do tertius comparativo que coloca o conhecimento teórico ou o saber explícito do(a) pesquisador(a) em segundo plano. A análise comparativa desempenha, assim, um papel de controle metodológico da compreensão da realidade estranha ou distante do universo do(a) pesquisador(a) - 'methodisch kontrolliertes Fremdverstehen' -, ou seja, de controle das afirmações ou generalizações realizadas sobre a realidade observada.

Para o método documentário, a análise comparativa tem ainda como objetivo a construção de tipos, que servirão como base para a elaboração de uma tipologia numa etapa posterior (cf. Bohnsack, 1989 e 2001c). A construção dos tipos orienta-se pelo princípio da busca dos contrastes em casos homólogos e pelo procedimento conhecido como amostra teorética 
(theoretical sampling), desenvolvido pelos fundadores da teoria fundamentada ${ }^{17}$. Trata-se de um processo circular que inicia com a identificação e explicação dos modelos de orientação e do habitus. Esta explicação só é possível através da inserção nos espaços sociais de experiências conjuntivas nos quais o(a) pesquisador(a) deverá orientar seu trabalho para a busca da gênese dessas orientações e não apenas para a interpretação das mesmas (Bohnsack, 1999, p. 159). Os indivíduos ou grupos pesquisados pertencem a distintos espaços de experiências conjuntivas (por exemplo: experiências geracionais, típicas da fase de desenvolvimento, relacionadas à formação escolar e/ou profissional, experiências relativas ao meio social, entre outras). Neste sentido, a construção de tipos exige uma abordagem multidimensional e uma sobreposição dos diferentes espaços de experiências conjuntivas. Quanto mais precisa for a construção de um tipo no qual as semelhanças e diferenças em relação a outros tipos tornam-se evidentes, tanto maior será o caráter de validade das teorias construídas empiricamente. Um tipo deixa de ser singular, quando comprovado que não é apenas específico daquele meio ou daquela realidade social (quando constatamos, por exemplo, grupos de orientação geracional e de orientação social-combativa tanto em São Paulo como em Berlim). A generalização dos resultados da análise empírica e a transformação deste conhecimento em teorias fundamentadas depende, portanto, da validade dos tipos construídos e da consolidação destes numa tipologia abrangente. Portanto, o método documentário de interpretação não está voltado para uma meIhor articulação entre teoria e empiria, mas para a própria produção de teorias, construídas a partir da análise criteriosa dos dados empíricos.

\footnotetext{
17 Segundo Strauss $(1994$, p. 70) a pergunta principal, que norteia o procedimento definido como theoretical sampling é a seguinte: Que grupos ou subgrupos populacionais, quais acontecimentos ou ações constituirão o próximo elemento de análise e, conseqüentemente, de levantamento de dados? Qual o interesse teórico que está por detrás? Dessa forma a coleta e análise dos dados é controlada pela teoria que se desenvolve nesse processo (cf. Glaser/Strauss, 1969, p. 45-77).
} 


\section{Considerações finais}

Com base na experiência aquirida, podemos afirmar que a proposta metodológica de Karl Mannheim e sua adaptação para a pesquisa qualitativa - como apresentada pelo sociólogo Ralf Bohnsack - constituíram uma base teórico-metodológica sólida e um importante instrumento de inserção nos distintos contextos sociais em que se realizou a pesquisa. O método documentário possibilitou uma compreensão maior das ações coletivas dos grupos pesquisados, uma sensibilidade e análise constante da postura do(a) pesquisador(a) em relação ao tema e aos atores envolvidos na pesquisa, assim como a reflexão teórica sobre as experiências cotidianas desses jovens.

Nesse sentido, o método documentário de interpretação se insere na tradição das metodologias qualitativas (cf. Gaskell \& Bauer, 2002, p. 481) e tem como características principais: a construção do corpus da pesquisa fundamentada no princípio da amostra teorética (theoretical sampling); a triangulação de distintas técnicas de coleta de dados; a transparência e clareza dos procedimentos utilizados; a descrição detalhada e o controle metodológico do processo de interpretação através da análise comparativa. Desde que o rigor metodológico - das etapas iniciais da pesquisa à construção de tipos e de sua validação - passou a predominar nas pesquisas qualitativas, o antigo argumento a respeito da representatividade de seus resultados deixou de fazer sentido. Atualmente, metodologias qualitativas não mais se apresentam como oposição aos métodos quantitativos, mas como enfoques diferentes e necessários no campo da pesquisa social empírica.

Por último, vale ressaltar que o método documentário não foi concebido somente para a análise de entrevistas individuais e grupais. Outras pesquisas utilizaram o método na interpretação de fotografias, imagens e vídeos (entre outros: Bohnsack, 2001; Michel, 2001 e Wagner-Willi, 2001) 
Exemplificação das etapas de transcrição e interpretação de entrevistas segundo o método documentário de interpretação

\section{ANEXO I}

\section{Organização temática da entrevista realizada com o grupo Skateboard}

Fita 1 - lado A

$00.15-12.12$
TP (Tema principal): Surgimento do grupo - Passagem: hip hop

Pergunta inicial: Como é que surgiu o grupo de vocês, como vocês se conheceram (.) e re- resolveram montar a banda?

$12.32-18.44$ TP: A vida na Cohab Fernandes - Passagem: Milieu

$18.44-28.57$ $28.57-39.40$ TP: Relação com namoradas/esposas - Passagem: Mulheres TP: Filhos (tema iniciado por Bm)

$39.40-44.40$ TP: Relação com os pais - Passagem: Pais

$44.40-47.30$

TP: Relação com irmãos

\section{Lado B}

$00.03-02.54$

TP: Relação com irmãos

$02.54-05.08$

TP: Relação com as gerações mais velhas

$05.42-08.20$

TP: Temas das letras de Rap - Passagem: Rap

$08.20-16.28$

TP: Experiências na escola

$16.55-25.10$

TP: Escola versus Trabalho - Passagem: Escola/Trabalho

$25.10-35.05$

TP: Experiências com violência policial

$35.22-47.30$

TP: Experiências discriminatórias - Passagem: Discriminação

Fita II - lado A

$00.05-11.30$

TP: Racismo no cotidiano

$11.30-16.15$

TP: Migrantes nordestinos na Cohab Fernandes

$16.15-21.20$

TP: Drogas no bairro (tema iniciado por $\mathrm{Cm}$ )

$21.20-39.05$

TP: Hip Hop no Brasil (tema iniciado por Am)

$39.05-44.45$

TP: Letras de rap e o papel do DJ na banda Skateboard 
Observação: Somente as passagens em negrito foram transcritas e analisadas. A organização temática não exige uma transcrição completa da entrevista. A escolha das passagens a serem transcritas seguiu os seguintes critérios: a) relevância do tema para o grupo (o que pode ser verificado pela densidade e dramaturgia, bem como pela participação de grande parte dos integrantes durante a discussão do tema em questão); b) importância do tema para a pesquisa; c) relevância da passagem para a comparação com outros grupos e para a reconstrução das orientações coletivas ou visões de mundo dos jovens pesquisados.

\section{ANEXO II}

\section{Códigos de transcrição}

Y: $\quad$ Abreviação para entrevistador (quando realizada por mais de um entrevistador, utiliza-se Y1 e Y2);

Am/Bf: Abreviação para entrevistado/entrevistada. Utiliza-se " $m$ " para entrevistados do sexo masculino e "f" para pessoas do sexo feminino. Numa discussão de grupo com duas mulheres e dois homens, por exemplo, utiliza-se: Af, Bf, Cm, Dm e dá-se um nome fictício ao grupo. Essa codificação será mantida em todos os levantamentos subseqüentes com as mesmas pessoas. Na realização de uma entrevista narrativo-biográfica com um integrante do grupo entrevistado anteriormente, costuma-se utilizar um nome fictício que inicie com a letra que a pessoa recebeu na codificação anterior (por ex.: Cm, Carlos);

?m ou ?f: Utiliza-se quando não houve possibilidade de identificar a pessoa que falou (acontece algumas vezes em discussões de grupo quando mais pessoas falam ao mesmo tempo);

(.) Pausa inferior a um segundo; 
(2) O número entre parênteses expressa o tempo de duração de uma pausa (em segundos);

L Utilizado para marcar colocações iniciadas antes da conclusão da fala de outra pessoa ou que iniciaram em seguida;

; $\quad$ Leve diminuição da entonação da voz ;

Forte diminuição da entonação da voz;

Leve aumento da entonação da voz;

? $\quad$ Forte aumento da entonação da voz;

exem- Palavra foi pronunciada pela metade;

exe:::mplo Pronúncia da palavra foi esticada (a quantidade de ::: equivale ao tempo da pronúncia);

assim =assim Palavras pronunciadas de forma emendada;

exemplo Palavra pronunciada enfaticamente;

${ }^{\circ}$ exemplo ${ }^{\circ} \quad$ Palavras ou frase pronunciada em voz baixa;

exemplo Palavras ou frase pronunciada em voz alta;

(example) Palavras cuja compreensão não está totalmente clara são colocadas entre parênteses;

( ) Parênteses vazios expressam a omissão de uma palavra ou frase que não foi compreendida (o tamanho do espaço vazio entre parênteses varia de acordo com o tamanho da palavra ou frase);

@exemplo@Palavras ou frases pronunciadas entre risos;

@(2)@ Número entre sinais de arroba expressa a duração dos risos;

((bocejo)) Expressões não-verbais ou comentários sobre acontecimentos externos, por exemplo: ((pessoa acende cigarro)), ((pessoa entra na 
sala e a entrevista é brevemente interrompida));

//hm// Utilizado apenas na transcrição de entrevistas narrativo-biográficas para indicar sinais de feedback ("ah", "oh", "mhm") ou risos do entrevistador (//(@(2)@//). Na transcrição das entrevistas de grupo esses ANiexiorãp destacados numa linha nova.

\section{Entrevista com o Grupo Skateboard (São Paulo). Transcrição da passagem hip hop}

1 Y: $\quad$ Como é que surgiu o grupo de vocês, como vocês

se

2

conheceram (.) e re- resolveram montar a banda?

(2)

3

$4 \quad$ Am: Qué falá primero, fala aí que você fala poco @(1)@

5 Bm:

Não (.)

6

pode começá o Am (.) o Am é o nosso porta voz né

a

Am:

gente só vai complementando mesmo

9

começou

10 assim a gente já tinha cada um já tinha uma- cada

um

11 não o $\mathrm{Bm}$ não tocava ainda e o $\mathrm{Cm}$ ele tinha uma outra

12 banda que eu não me lembro o nome agora

$13 \mathrm{Cm}$ : LEstado Negro

14 Am: LEstado Negro e eu tinha

uma outra 
15

16 Café e

que era o o Domínio Público né que atuava com os rapazes lá de Diadema né; que era o Rato e o aí, só que houve problema em ambas as partes ele com o grupo dele e eu com o meu e assim a gente viu que

um vê dava prá fazer alguma coisa junto começô a gostá

da música do otro e né vê que tinha alguma coisa a ê então

né assim as idéias batiam pelo menos em termos de letra tava batendo@(1)@ aí a (gente=falou) ah fazê; também

vamo vê o que que acontece vamo vê se dá prá

só que aí (.) eu já tava junto com o Mário né

que tinha otro grupo; então basicamente dos três

$$
\text { assim de otras bandas né então terminou as otras }
$$
bandas e a gente veio formá o Skateboard e o Bm

né é né

porque já tinha já tinha uma amizade já faz te::mpo a as 31 idéias batendo e vendo no que dava e:: faz dois anos

$33 \mathrm{Cm}$ : né? que a gente tá faz dois anos

34 Am: LÉ faz dois anos também gostava de rap e tal e também ficou junto e gente formou a banda assim né conversando vendo 
dois anos

35 praticamente é dois anos sim dois anos que a banda já

36 existe e agora a gente tá fazendo um trabalho mais forte de

38 vê como tava as letras é:: arrumando treinando as

39 músicas e tudo mais prá fazê um estilo diferente uma

40 coisa nova; e aí agora ( )

$41 \mathrm{Cm}$ : $\quad$ É e fora isso a gente tava vendo

42 a aceitação do público também

43 Am:

44 Bm: público

45 diferente; sem ser envolvido somente com rap né (1)

47 Bm: (a gente não pode) principalmente com o povo

48 esqueitista e o pessoal do samba

49 Am:

na

50 verdade o rap fica muito: é o rap não as outras bandas

51 de rap ficam muito assim

$52 \mathrm{Bm}$ :

53 Am:

LÉ só

54 pro rap mesmo então a gente já tá procurando fazê uma

55 coisa diferente MPB, se der rock, foró também se quisé 
vim pode vim, desde que ( ) né dê prá fazê uma junção

57 das coisas né uni tudo porque a gente sabe que tem

$58 \quad$ Y: $\quad$ L Hm

59 Am: coisas boas por outro lado não só no rap né o rap é um

60 é só uma continuidade das- dos outros trabalhos porque

61 blues então

a base de tudo hoje em dia é o MPB, é o jazz o

$$
{ }^{\circ} \text { entendeu }{ }^{\circ} \text { a base né que deu origem pro rap na }
$$
verdade. então a gente não pode ignorar isso como não dá ${ }^{\circ}$ ntendeu ${ }^{\circ}$ a gente tem que (.) ampliá ${ }^{\circ e}$ aí vai $^{\circ}$

69 Y: E o que que significa o Hip Hop prá vocês, é:: porque rap, é

74 Bm: Bom praticamente prá mim foi mais o estilo né, ficava só

que vocês por exemplo se interessaram em cantar 
indo

81 (1) aprendendo a cultura também (2)

$82 \mathrm{Cm}$ : É e o rap assim a gente achava bem variado assim

na

83 questão da música tinha assim vamos supor o rap lento

tinha aquele mais agitado tinha aquele ma- aquele som jeito aí em cada música assim de determinados grupo que a gente se encontrava assim tá ligado tipo de do

de prá gente curtir igual veio o bate cabeça a gente aqui era febre também veio otros estilo aí foi indo assim mas tipo assim a gente só foi aprendendo um poco cada um prá gente formar o Skatebord tá ligado

Am: $\quad\lfloor\mathrm{Hm}$

Bm:

L Antes de aprender primeiro o hip hop

a gente primeiro só aprendeu a curtir a música prá depois a gente fo- foi se aprofundando mais (.) aí que surgiu mesmo tu- o grupo (1)

Am: É basicamente o- né assim acho que ca- prá começá

cantá mesmo né a conhecer o rap, o hip hop em si né é que nem cada um tem um (.) um jeito de começá

101 então no meu caso mesmo foi o lance da dança né 102 eu já dançava Break na época né na São Bento assim

103 Y:

104 Am: porque tinha né o movimento de Break na São Bento

105 e aí eu comecei a dançar e depois teve é a formação do

106 Sindicato Negro teve na Roosewelt eu participei 
um pouco,

107 não como integrante mas assim né visitava, via como que

108 era e aí eu falei ah porque não fazer um na na Fernandes

109 nonde porque era o único movimento assim de juventude

110 que ia ter na periferia a gente queria ser os pioneiros

111 ?m:

$(($ tosse $))$ ç

112 Y:

L Hm

113 Am: e aí foi quando eu conversei com o Carlos né, que aí

114 eu falei é vamo tentá fazer u- uma coisa igual está lá mas

115 aqui e aí a gente pegou e começou a bolá e aí juntou

116 só que o nome Estilo Negro ainda não tinha nem aparecido

117 ainda depois que a gente falou não, a gente precisa por

118 um nome alguma coisa que entendeu que as pessoas se

119 identifiquem com a gente né do que que é, ah é estilo

120 estilo de todo mundo e aí vamo colocá a cor então que a

121 maioria era negra né, a época majoritária do Estilo Negro

122 era negra então a gente começou assim a ver o rap nessa

123 forma, foi pela dança depois veio pelos grafites, pelos

124 desenhos né do pessoal que faz depois assim as letras

125 mesmo a gente foi conhecendo o trabalho 
comunitário e foi

126 vendo que tudo isso não era só um rap era o hip hop em si

127 né ${ }^{\circ}$ entendeu ${ }^{\circ}$ que era que tudo isso então né a formação

128 Y: $\quad$ Hm

129 Am: do Skateboard também veio por aí né, veio tudo de- desse

130 ponto de partida ${ }^{\circ}$ entendeu $^{\circ}(1)^{\circ}{ }^{\circ}$ então ${ }^{\circ}$ basicamente todo

131 mundo entrou por algum @motivo@ por algum vínculo

132 ?m:

133 Am: (.) se identificando com as músicas com o rap em si por-

134 porque né como diz o rap fala a vida de cada um então prá

135 gente que tem uma mente assim meio revolucionária né,

136 a gente tem, se identifica muito com o rap né, a gente ve

137 que é uma letra que (não) fala a verdade de cara, não fica

138 embroma::ndo entendeu, é não é que nem um MPB

139 que às vezes solta aquela coisa assim por fora

140 indiretamente (né)

$141 \mathrm{Cm}$ : LE às vezes é até um desabafo prá

gente

142 mesmo né assim tanto que a gente tem letras que fala

143 Am: LÉ

144 Y1: $\quad \mathrm{Hm}$

$145 \mathrm{Cm}$ : eu tenho letra que fala da minha vó que morreu o $\mathrm{Am}$

146 tem letra que fala tal de coisas que aconteceram

147 Am: ' ${ }^{\circ}$

148 Cm: com ele 
149 Am: $\quad$ Do pai de mãe (.) né ${ }^{\circ}$ então tem ele e bastante

150 coisa (.) que tem a ver ${ }^{\circ}$ com a gente (1) e basicamente é

151 isso né, no começo foi, foi isso daí ('não temº

\section{ANEXO IV}

\section{Interpretação refletida da passagem hip hop, Grupo Skateboard (São Paulo)}

69 - $72 \quad$ Pergunta imanente de Y (diretamente ligada ao tema que estava sendo discutido)

Após um intervalo de quatro segundos, $\mathrm{Y}$ dirige uma pergunta imanente ao grupo incentivando o debate sobre o significado do hip hop, principalmente dos motivos e interesses do grupo por esse estilo musical. 74 - 81 Proposição e elaboração através de Bm

Para $B m$, num primeiro momento, o que mais motivou foi o estilo e os momentos coletivos de "curtição". A vida no bairro é definida pela vivência no coletivo, que age sobre o indivíduo e sua identidade. A palavra estilo compreende um determinado modo de se vestir, a incorporação de uma linguagem e performance estético-corporal específica, bem como a apropriação de um tipo de produção textual e musical. Inicialmente, havia uma atração pré-reflexiva pelo estilo ("só curtia"); num segundo momento, passou a existir uma relação positiva com o mesmo ("aí acabei gostando"). Somente num terceiro momento surgiu o interesse pela "cultura", que pode ser interpretado como o interesse pela história do movimento hip hop que teve sua origem nos bairros novaiorquinos na década de 1970.

82 - 93 Validação e diferenciação através de Cm

Cm concorda com o que foi dito anteriormente ("é") e acrescenta as riquezas ou especificidades do rap ("lento, agitado, pesado"). Além do gosto pelo estilo havia a identificação com as histórias narradas, nas quais os jovens "se encontravam". As experiências individuais passam a ser vividas e 
trabalhadas de forma coletiva através das músicas.

94 - 97 Diferenciação através de Bm

O interesse pelo hip hop surgiu inicialmente pelos momentos coletivos de "curtição". Numa fase posterior, houve um aprofundamento do conhecimento sobre o movimento hip hop que levou à formação da banda. 98 - 108 Exemplificação através de Am

Segundo Am, cada jovem ingressa de uma forma ou de um "jeito" distinto no hip hop. Seu ingresso deu-se através da dança e da associação ao movimento break. Neste sentido, o período da dança representa a fase pré-reflexiva na trajetória de Am pelo movimento hip hop, enquanto, para $\mathrm{Bm}$ e $\mathrm{Cm}$, a fase pré-reflexiva corresponde ao momento em que aprenderam a "curtir" a música que chegava na periferia. Para Am, a cultura hip hop na periferia surgiu com o espírito pioneiro por parte dos jovens que levaram "esse movimento de juventude" para o próprio bairro. A descolocação do hip hop do centro (São Bento, Roosewelt) para a periferia resulta deste processo de amadurecimento e reflexão, que, ao mesmo tempo, atribui um novo sentido e significado ao movimento, haja vista que a maioria dos jovens negros vivem na periferia e não no centro da cidade.

108 - 133 Exemplificação e reformulação da proposição através de Am

Com a vinda do hip hop para a periferia através da organização da Posse Estilo Negro, além dos elementos centrais - Grafite, Breakdance e Rap -, um novo aspecto passou a fazer parte do movimento, que Am descreve como "trabalho comunitário". O rap corresponde à parte artístico-musical e recreativa do movimento, enquanto o hip hop como um todo está associado não apenas aos aspectos lúdicos, mas também às atividades políticas e sociais desenvolvidas pelos jovens. O trabalho comunitário surge como uma tentativa de solução da ambivalência existente entre "rap" e "gueto", ou seja, entre o rap como elemento recreativo e a realidade do bairro, que não pode ser vista ou abordada somente no palco. Desta forma, o grupo denuncia os problemas vividos no bairro através da música e desenvolve paralela- 
mente ações concretas com o objetivo de transformar, ou, pelo menos, de amenizar esta realidade.

\section{4 - 140 Elaboração através de Am}

Am retoma o tema 'identificação com o rap', que havia sido discutido anteriormente por $\mathrm{Cm}$, e acrescenta que a forte associação com o rap está relacionada à "mente revolucionária" do grupo. O rap não representa somente lazer e consumo: ele é acima de tudo um símbolo da juventude "revolucionária", um instrumento que "fala a verdade de cara, [que] não fica embromando". Nesse sentido, a palavra "verdade" significa denúncia explícita dos problemas vividos no bairro, como o desemprego, a violência, a criminalidade, as drogas, as moradias precárias, o escasso atendimento no campo da saúde e da educação. Ao mesmo tempo, a distinção entre rap e MPB é realizada com o intuito de revelar a particularidade e exclusividade do pensamento "revolucionário" da geração que se identifica com o rap.

\section{1 - 151 Proposição através de Cm e Am}

$\mathrm{Cm}$ acrescenta que o rap também é uma forma de "desabafo", ou seja, uma forma de superar experiências traumáticas vividas na família, por exemplo, a perda da avó [Obs.: Trata-se da avó que criou Cm]. Experiências individuais - "coisas que aconteceram" - são trabalhadas no processo de elaboração de uma letra de rap, e, ao mesmo tempo, partilhadas com o coletivo. O rap passa a ser uma forma de análise dessas experiências, tanto com os integrantes do grupo como com o público. Nesse sentido, o rap não está relacionado apenas ao contexto do lazer e das manifestações políticas destes jovens, mas também às experiências vividas no interior da família. 


\section{Referências}

BLASKIE, Norman. Designing social research. The logic of anticipation. London: Polity Press, 1993.

BOHNSACK, Ralf. Generation, Milieu und Geschlecht. Opladen: Leske + Budrich, 1989.

BOHNSACK, Ralf. Rekonstruktive Sozialforschung - Einführung in Methodologie und Praxis qualitativer Forschung (3aㅡ Ed.). Opladen: Leske + Budrich, 1999.

BOHNSACK, Ralf. Karl Mannheim (Conferência de abertura do seminário de leitura sobre Karl Mannheim). Universidade Livre de Berlim, semestre de inverno 1999/2000 (mimeo), 1999a.

BOHNSACK, Ralf. Dokumentarische Methode. Theorie und Praxis wissenssoziologischer Interpretation. In: HUG, Theo (org.). Wie kommt Wissenschaft zu Wissen? Band 3, Einführung in die Methodologie der Sozial- und Kulturwissenschaften. Baltmannsweiler: Schneider-Ver. Hohengehren, 2001. p. 326-345.

BOHNSACK, Ralf. Die dokumentarische Methode in der Bild- und Fotointerpretation. In: BOHNSACK, Ralf et al. Die Dokumentarische Methode und ihrer Forschungspraxis. Opladen: Leske + Budrich, 2001. p. 67-89.

BOHNSACK, Ralf; NOHL, Arnd-Michael \& NENTWIG-GESEMANN, Iris. Die Dokumentarische Methode und ihrer Forschungspraxis. Opladen: Leske + Budrich, 2001.

BOHNSACK, Ralf \& NOHL, Arnd-Michael. Ethnisierung und Differenzerfahrung. Fremdheit als alltägliches und als methodologisches Problem. Zeitschrift für qualitative Bildungs-, Beratungs- und Sozialforschung, n. 1, p. 15-36. 2001b.

BOHNSACK, Ralf. Typenbildung, Generalisierung und komparative Analyse. Grundprinzipien der dokumentarischen Methode. In: idem et al. Die Dokumentarische Methode und ihre Forschungspraxis. Opladen: Leske + Budrich, 2001c. p. 225-252.

BOHNSACK, Ralf. The Documentary Method Exemplified by the Interpretation of Group Discussions. Presentation at the WEU-Workshop at Münster (mimeo). 2002. 
COULON, Alain. Etnometodologia. Petrópolis: Vozes, 1995.

FABIANI, Jean-Louis. O que resta do agente social? A análise sociológica frente à exemplaridade biográfica e à diminuição de si. Tempo Social, São Paulo, v. 14, n. 1, p. 33-65. 2002.

GASKEL, George \& BAUER, Martin W. Para uma prestação de contas pública: Além da amostra, da fidedignidade e da validade. In: idem (ed.): Pesquisa qualitativa com texto, imagem e som. Um manual prático. Petrópolis: Vozes, 2002. p. 470-490.

GARCíA, José M. González. Reflexiones sobre «El Pensamiento Conservador» de Karl Mannheim. Revista española de investigaciones sociológicas, n. 62, p. 6181. 1993.

GARFINKEL, Harold. Common sense knowledge of social structures: the documentary method of interpretation in lay and professional fact finding. In: idem. Studies in Ethnomethodology. New Jersey: Englewood Cliffs, 1967. p. 76-96.

GLASER, Barney \& STRAUSS, Anselm. The discovery of Grounded Theory: Strategies for Qualitative Research. Chicago, 1967.

GOFFMAN, Erving. Rahmen-Analyse: Ein Versuch über die Organisation von

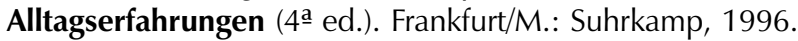

HERITAGE, John C. Etnometodologia. In: GIDDENS, Anthony \& TURNER, Jonathan (orgs.). Teoria social hoje. São Paulo, Editora da UNESP, 1999. p. 321-392.

JOVCHELOVITCH, Sandra \& BAUER, Martin W. Entrevista narrativa. In: GASKEL, George \& BAUER, Martin W. (ed.): Pesquisa qualitativa com texto, imagem e som. Um manual prático. Petrópolis: Vozes, 2002. p. 90-113.

JOSEPH, Isaac. Erving Goffman e a Microsociologia. Rio de Janeiro: Editora FGV, 2000.

KETTLER, David et al. Introduction. In: MANNHEIM, Karl. Structures of thinking. Collected Works Volume Ten. London: Routledge \& Kegan Paul, 1982. p. 11-29.

LANG, Alice B.S.G. História oral: procedimentos e possibilidades. In: idem et al. (orgs.). Desafios da pesquisa em Ciências Sociais. São Paulo: CERU, Textos 8, Série 2, p. 91-109, 2001. 
LUHMANN, Niklas. Beobachten. In: idem. Die Wissenschaft der Gesellschaft. Frankfurt/M.: Suhrkamp, 1992. p. 68-121.

MANNHEIM, Karl. Wissenssoziologie. In: idem. Ideologie und Utopie. Frankfurt/ M.: Klostermann, 1952. p. 227-267.

MANNHEIM, Karl. Beiträge zur Theorie der Weltanschaungsinterpretation. Wissenssoziologie. Neuwied, Luchterhand, 1964, p. 91-154 [inglês: Essays on the sociology of Knowledge. London: Routledge + Kegan Paul, 1952, 33-83].

MANNHEIM, Karl. Strukturen des Denkens. Frankfurt/M.: Suhrkamp, 1980 [inglês: Structures of thinking. Collected Works Volume Ten. London: Routledge + Kegan Paul, 1982].

MICHEL, Burkard. Fotografien und ihre Lesarten. Dokumentarische Interpretation von Bildrezeptionsprozessen. In: BOHNSACK, Ralf et al. Die Dokumentarische Methode und ihrer Forschungspraxis. Opladen: Leske + Budrich, 2001. p. 91-120.

MELLA, Orlando. (1998) Naturaleza y orientaciones teórico-metodológicas de la investigación cualitativa. Disponível em: < http://www.reduc.cl/reduc/ mella.pdf>. Acesso em: 29 abril. 2003.

MEUSER, Michael. Repräsentation sozialer Strukturen im Wissen. Dokumentarische Methode und Habitusrekonstruktion. In: BOHNSACK, Ralf et al. Die Dokumentarische Methode und ihre Forschungspraxis. Opladen: Leske + Budrich, 2001. p. 207-221.

MUÑOZ, J. Carlos Gómez. El retorno de la sociología del conocimiento de Mannheim a una epistemología de corte weberiano. Revista española de investigaciones sociológicas, n. 62, p. 45-59, 1993.

NEVES, Clarissa E. B. Apresentação - Pesquisa social empírica: Métodos e Técnicas. Cadernos de Sociologia, Porto Alegre, vol. 9, p. 7-9, 1998.

NOHL, Arnd-Michael. Komparative Analyse: Forschungspraxis und Methodologie dokumentarischer Interpretation. In: BOHNSACK, Ralf et al. Die Dokumentarische Methode und ihre Forschungspraxis. Opladen: Leske + Budrich , 2001, p. 253-273.

ORTIZ, Renato. A procura de uma sociologia da prática. São Paulo: Ática, 1983. 
PAIS, José Machado. Vida cotidiana: enigmas e revelações. São Paulo: Cortez, 2003. POLANYI, Michael. Implizites Wissen. Frankfurt/M.: Suhrkamp, 1985.

REICHERTZ, Jo. Die Abduktion in der qualitativen Sozialforschung. Opladen: Leske + Budrich, 2003.

STRAUSS, Anselm. Grundlagen qualitativer Sozialforschung. München: W. Fink, 1994.

WAGNER-WILLI, Monika. Videoanalysen des Schulalltags. Die dokumentarische Interpretation schulischer Übergangsrituale. In: BOHNSACK, Ralf et al. Die Dokumentarische Methode und ihrer Forschungspraxis. Opladen: Leske + Budrich, 2001. p. 121-140.

WELLER, Wivian. HipHop in São Paulo und Berlin: Ästhetische Praxis und Ausgrenzungserfahrungen junger Schwarzen und Migranten. Opladen: Leske + Budrich, 2003.

WELLER, Wivian. O hip hop nas cidades de São Paulo e Berlim: orientações coletivas e estratégias de superação do racismo de jovens negros e jovens de origem turca. In: Anais do XXVI Encontro Anual da ANPOCS. GT 17: Relações raciais e etnicidade. Caxambu, 22 a 26 de outubro de 2002.

WELLER, Wivian. O hip hop como possibilidade de inclusão e de enfrentamento da discriminação e da segregação na periferia de São Paulo. Caderno CRH, Salvador, v. 17, n. 40, p. 103-115, Jan/Abr. 2004.

WELLER, Wivian et al. Karl Mannheim e o método documentário de interpretação: Uma forma de análise das visões de mundo. Estado e Sociedade. Revista do Departamento de Sociologia da UnB, v. XVII, n. 02 [Inovações no Campo da Metodologia das Ciências Sociais], p. 375-396, Jul./Dez. 2002.

YNCERA, Ignacio Sánchez de la. (1993a) Crisis y orientación. Apuntes sobre el pensamiento de Karl Mannheim. Revista española de investigaciones sociológicas, n. 62, p. 17-43, 1993.

YNCERA, Ignacio Sánchez de la. (1993b) La obra de Karl Mannheim. Una compilación actualizada de sus escritos más relevantes. Revista española de investigaciones sociológicas, n. 62, p. 245-253, 1993.

Recebido: 18/03/2004

Revisado: 17/06/2004

Aceite final: 27/08/2004 
Sociologias, Porto Alegre, ano 7, no 13, jan/jun 2005, p. 260-300

\section{Resumo}

O presente trabalho retoma a contribuição de Karl Mannheim na construção de um método interpretativo de pesquisa. Discute as reflexões metodológicas e o desenvolvimento de um método de análise das visões de mundo, denominado método documentário de interpretação. A Etnometodologia foi a primeira corrente teórico-metodológica a reconhecer a importância do método documentário de interpretação de Karl Mannheim para a análise de dados qualitativos. Na Alemanha, o sociólogo Ralf Bohnsack retomou e atualizou o método documentário, tanto do ponto de vista do método como da metodologia, transformando-o numa ferramenta de análise de entrevistas individuais e grupais, imagens, fotografias e documentos. O método documentário como teoria e prática da interpretação sociológica pode ser visto como um instrumento que permite a inserção do(a) pesquisador(a) nos contextos sociais alheios, a compreensão e conceituação das visões de mundo ou orientações coletivas de um grupo, suas ações e formas de representação. Nesse sentido, o método documentário de interpretação transcende o nível da análise intuitiva ou dedutiva e instiga a construção de instrumentos analíticos capazes de mapear e dar forma às experiências cotidianas, que carecem de reflexão teórica.

Palavras-chave: Karl Mannheim, pesquisa qualitativa, método documentário de interpretação, análise de entrevistas. 


\section{Karl Mannheim's contribution to qualitative research: theoretical and methodological aspects}

\section{Wivian Weller}

The present work resumes Karl Mannheim's contribution to the construction of an interpretive research method. It discusses methodological reflections and the development of a method of analysis of worldviews called documentary method of interpretation. Ethnomethodology was the first theoretical-methodological line of thought to recognize the importance of Karl Mannheim's documentary method of interpretation for the analysis of quantitative data. In Germany, sociologist Ralf Bohnsack resumed and updated the documentary method both from the point of view of method and methodology, turning it into a tool to analyze individual and group interviews, images, photographs, and documents. The documentary method as theory and practice of sociological interpretation can be seen as an instrument that allows to place the researcher in unknown social contexts, understanding and conceptualizing worldviews or collective orientations of a group as well as its actions and ways of representations. Therefore, the documentary method transcends the level of intuitive or deductive analysis and instigates the construction of analytical instruments able to map and shape everyday experiences, which lack theoretical reflection.

Key words: Karl Mannheim, Qualitative research, Documentary method of interpretation, Analysis of interviews. 